\title{
Knowledge of COVID-19 among Health Care Workers at a Tertiary Care Hospital of Nepal: A Descriptive Cross-sectional Study
}

\author{
Sandip Bhandari, ${ }^{1}$ Medha Sharma, ${ }^{2}$ Gentle Sundar Shrestha ${ }^{3}$ \\ 'Department of Anaesthesiology, Shahid Gangalal National Heart Centre, Kathmandu, Nepal, ${ }^{2}$ Visible Impact, \\ Kathmandu, Nepal, ${ }^{3}$ Department of Anaesthesiology, Tribhuvan University Teaching Hospital, Maharajguni, \\ Kathmandu, Nepal.
}

\section{ABSTRACT}

Introduction: Health care workers are at higher risk of infection with the coronavirus disease as they are directly involved in the treatment of infected patients and perform aerosol-generating procedures. Proper knowledge of this disease can influence the positive attitude, good practices and enhance their safety. We aim to study the knowledge of COVID-19 among health care workers of the tertiary care hospital of Nepal.

Methods: A descriptive cross-sectional study was conducted among health care workers of Shahid Gangalal National Heart Centre from May 20 to June 19, 2020. Ethical approval was taken from the Institutional Review Board (IRB No: 4-2020). Written informed consent was taken from all respondents. Correct answers were summated to reflect the mean knowledge, expressed as a percentage. Data analysis was done using Statistical Package for the Social Sciences version 21.

Results: The mean general knowledge score was $95.7 \%$. The mean medical knowledge score was $70.5 \%$. Only $42(56.8 \%)$ of physicians and $103(53.6 \%)$ of nurses had a higher level of medical knowledge regarding COVID-19. Likewise, very few lab technicians 7 (21.9\%) and none of the pharmacists had a higher level of medical knowledge.

Conclusions: The healthcare workers of this centre have adequate knowledge regarding COVID-19. However, periodic training for all workers, especially the nurses and allied workers, may help to update the knowledge and hence enhance their safety and that of their patients.

Keywords: Corona-virus disease; health care workers; knowledge.

\section{INTRODUCTION}

Health care workers (HCWs) are at risk of Coronavirus disease (COVID-19) because of prolonged and repeated exposure to patients and because HCWs work in a team and physical distancing is usually not possible among them. ${ }^{1} \mathrm{HCW}$ of the cardiac centre are at even heightened as COVID-19 can manifest or precipitate as cardiovascular emergencies and also due to their involvement in aerosol-generating procedures (AGP). ${ }^{2}$

Poor knowledge and misunderstanding have been found to lead to delayed treatment, ${ }^{3}$ recognition, and handling of potential COVID-19 patients, ultimately leading to its rapid spread in hospitals. ${ }^{4,5}$
Thus, this study aims to investigate the knowledge of COVID-19 among HCWs of tertiary level cardiac care hospital in Nepal. This will help to generate evidence that can support the hospital management to design interventions to ensure the safety of HCWs and patients at this time of the pandemic.

\section{METHODS}

This is a descriptive cross-sectional study conducted

Correspondence: Dr. Sandip Bhandari, Department of Anaesthesiology, Shahid Gangalal National Heart Centre, Bansbari, Kathmandu, Nepal. Email: sandipbhandari@hotmail.com,Phone: +977-9851115629. 
among HCWs of Shahid Gangalal National Heart Centre from May 20 to June 19, 2020. Ethical approval was taken from Institutional review board (IRB No: 4-2020), Shahid Gangalal National Heart Centre and written informed consent was taken from all respondents. Participants were enrolled using convenient sampling technique. The sample size was calculated using the formula,

$\mathrm{n}=\mathrm{Z}^{2} \times \mathrm{p} \times(1-\mathrm{p}) / \mathrm{e}^{2}$

$=(1.96)^{2} \times 0.5 \times 0.5 /(0.06)^{2}$

$=267$

Where,

$\mathrm{n}=$ sample size

$Z=1.96$ at $95 \%$ Confidence Interval $(\mathrm{Cl})$

$\mathrm{p}=$ population proportion, $50 \%$

$\mathrm{e}=$ margin of error, $6 \%$

Taking a $10 \%$ non-respondent rate, the sample size became 294. However, data was collected from 305 HCWs.

The data was collected through a self-administered questionnaire, consisting of three sections: sociodemography, general knowledge, and medical knowledge. Correct answers were summated to reflect the mean knowledge, expressed as a percentage. The socio-economic status was analyzed using 5 household items (mobile, house, laptop, vehicle, internet). ${ }^{6}$

Data analysis was done using Statistical Package for the Social Sciences (SPSS) version 21.

\section{RESULTS}

The mean basic score was 95.7\%. All general knowledge factors were answered correctly by more than $90 \%$ of respondents except for the knowledge related to disease symptoms, which was correctly answered by 219 $(71.8 \%)$ of respondents only. General knowledge about COVID-19 was assessed using 10 factors (Table 1 ).

\section{Table 1. General knowledge components of the COVID-19 questionnaire and the correct responses.}

\section{Questions}

Correct re-

sponses $\mathbf{n}$

(\%)

1. The COVID-19 virus (SARSCoV-2) spreads via respiratory droplets of infected individuals.

2. There currently is no effective cure for COVID-19 but early symptomatic and supportive treatment can help with most patients recover from the infection.

3. Health care workers are at higher risk of infection.

301 (98.7)
4. The main clinical symptoms of COVID-19 are fever, fatigue, sore throat, dry cough and myal- 304 (99.7) gia.

5. To prevent the infection by COVID-19 individuals should avoid going to crowded places such as the gym, theatres and avoid public transportation.

6. Isolation and treatment of people who are infected with the COVID-19 virus are effective $303(99.3)$ ways to reduce the spread of the virus.

7. Unlike the common cold, stuffy nose, runny nose, and sneezing are less common in persons $219(71.8)$ infected with the COVID-19.

8. A vaccine is now publicly available for COVID-19.

9. Contact persons should be isolated for at least 14 days.

10. Hand hygiene, covering nose and mouth while coughing, and avoiding sick contacts can help in the prevention of COVID-19 305 (100) transmission.

The mean medical knowledge score was $70.5 \%$. Dichotomizing the medical knowledge score through the median, only $56.8 \%$ of physicians and $53.6 \%$ of nurses had a higher level of medical knowledge regarding COVID-19. None of the pharmacists and only $21.9 \%$ of lab technicians/radiographers had a higher level of medical knowledge.

Regarding the N95 respirators, only 141 (46.2\%) and $92(30.2 \%)$ of $\mathrm{HCWs}$ respectively knew that they are not recommended for use in OPD and triage room respectively. However, 268 (87.9\%) knew they should be used during tracheal intubation. Regarding PPE, 262 (85.9\%), 268 (87.9\%) and 254 (83.3\%) of HCWs respectively knew that they are used in tracheal intubation, surgery of suspected case, and for collecting the respiratory sample. However, only 138 (45.2\%) knew that they are not recommended for use in OPD of infectious disease. The importance of category I PPE donning during CPR for potential COVID-19 patients is known to 294 (96.4\%) of HCWs. And 143 (46.9\%) and 277 (90.8\%) of HCWs respectively knew that patients should be intubated early and experts should do it. The recommendation for not giving rescue breathing is known by $235(77 \%)$ HCWs. Regarding the infection reduction, $278(91 \%)$ and $253(83 \%)$ of HCWs knew that COVID-19 infection can be reduced by separating COVID and non-COVID patients and staff education respectively. Only124 (40.7\%) knew it can be reduced 
by decreased mobile use.

Only 167 (54.8\%) of respondents knew about the correct use of surgical and N95 masks. Only 120 $(39.3 \%)$ knew that these masks can be sterilized. A very high proportion 252 (82\%) of HCWs knew alcohol can't and $248(81.3 \%)$ knew that UV light can sterilize them (Table 2).

\begin{tabular}{|c|c|}
\hline Knowledge Factors & $\begin{array}{l}\text { Correct } \\
\text { response n (\%) }\end{array}$ \\
\hline $\begin{array}{l}\text { 1. Antibiotics as the first line of } \\
\text { treatment for COVID-19 }\end{array}$ & $251(82.3)$ \\
\hline 2. Use of surgical mask for non-AGP & $279(91.5)$ \\
\hline $\begin{array}{l}\text { 3. Persons with COVID- } 19 \text { cannot } \\
\text { infect the virus to others when } \\
\text { the fever is not present? }\end{array}$ & $291(95.4)$ \\
\hline $\begin{array}{l}\text { 4. Recommendation of use of } \mathrm{N} 95 \\
\text { respirator }\end{array}$ & $196(64.3)$ \\
\hline 5. Requirement of PPE & $230(75.6)$ \\
\hline $\begin{array}{l}\text { 6. Regarding the decrease of } \\
\text { COVID-19 spread }\end{array}$ & 201 (65.9) \\
\hline $\begin{array}{l}\text { 7. CPR for potential COVID-19 } \\
\text { patients }\end{array}$ & $237(77.8)$ \\
\hline $\begin{array}{l}\text { 8. Regarding reuse and sterilization } \\
\text { of surgical and N95 mask }\end{array}$ & $167(54.8)$ \\
\hline
\end{tabular}

The source of knowledge regarding COVID-19 was mostly social media (87\%), while $62 \%, 60 \%$, and $56 \%$ of respondents referred to digital media, national TV/ radio, and friends or relatives to obtain such information respectively. Interestingly, only $2.29 \%$ of HCWs referred to more authentic sources such as classes, webinars, and journals for information.

Out of 305 HCWs, 192 (63\%) were nurses, 75 (24.5\%) physicians, 32 (10.5\%) lab technicians/ radiographer, and $6(2 \%)$ pharmacists. The mean age of the respondents was $31.2+6.7$ years, (range; $20-59$ years). Approximately $55 \%$ of the respondents were aged 20-30 years. Most (74.1\%) were female. Most $(60.3 \%)$ respondents were married/living together. Ethnic groups were almost equally represented (Janajati $=37.4 \%$, Brahmin $=31.1 \%$, Chhetri $=31.1 \%$ ) . The mean economic status was $68 \%$. Approximately $44.3 \%, 54.7 \%$ and $2 \%$ of $\mathrm{HCWs}$ were on higher, moderate and lower economic category respectively. The mean years of professional experience were $8.3+6.9$ years (range; $1-36$ years) .

\section{DISCUSSION}

COVID-19 has emerged as a significant public health concern, especially after the World Health Organisation (WHO) declared it as a pandemic on $11^{\text {th }}$ March $2020 .{ }^{7}$
Nepal had its first COVID-19 case on January 24, 2020. As of 13 July 2020, Nepal has 17,658 cases with 40 mortalities. Till date, $85 \mathrm{HCWs}$ have been infected with COVID-19 but no mortality has been reported yet. ${ }^{8}$

Patients of cardiovascular comorbidity are at higher risk of contracting COVID-19 and have a worse prognosis with a case fatality rate of $10.5 \%$ which is higher than the average population. ${ }^{2}$ COVID-19 patient may present as a direct manifestation of or precipitation of previous cardiac symptoms. Their classic symptoms and presentation may be overshadowed leading to under-diagnosis. ${ }^{2}$ When patients present with cardiovascular emergencies like acute myocardial infarction, arrhythmias, heart failure, etc. There is no time to confirm or rule out COVID-19and HCWs in such settings might need to perform AGP such as tracheal intubation, cardiopulmonary resuscitation (CPR), respiratory sample collection, etc. ${ }^{2}$ Due to prolonged and repeated exposure to patients, and the job nature of working in a team, physical distancing is usually not possible among HCWs. ${ }^{1}$ Likewise, limited knowledge of the disease itself, limited availability and improper donning and doffing of personal protective equipment (PPE), etc. might increase the risks of COVID-19 infection. ${ }^{1}$ Hence, HCWs working in cardiac centre are at heightened risk of COVID-19 infection.

As no definitive antiviral treatment or vaccine has been explicitly recommended for COVID-19, exercising preventive measures to control its spread is the only most widely accepted intervention recommended.9 As HCWs are involved in the treatment of COVID-19 patients, their knowledge of prevention of disease transmission becomes must so that they can prevent COVID-19 infection by decreasing the risk of transmission, recognizing symptoms early, and assisting in diagnosis. When this disease became pandemic earlier this year, online courses for awareness of $\mathrm{HCW}$ s were initiated 10 regarding COVID-19. However, the level of knowledge of this disease among HCWs in Nepal is still largely unknown. Thus, this research aimed to investigate knowledge of HCWs about the COVID-19 in a national cardiac care centre of Nepal.

The mean general knowledge score in this study (95.7\%) was slightly higher than the study by Huynh et al. ${ }^{11}$ and Zhang et al. ${ }^{12}$ where $88.4 \%$ HCWs and $89 \%$ HCWs demonstrated sufficient knowledge of COVID-19. Also, knowledge score of preventive measures such as avoiding crowded places like gym, theatres, and public transportation, etc. isolation of people infected with COVID-19 as effective measures to reduce the spread of the virus are quite higher compared to similar studies. In the study done by Huynh et al, the contact person should be in isolation for at least 14 days is known by $65.8 \%$ HCWs only ${ }^{11}$ which is known by $97.4 \%$ 
HCWs in our study. Similarly, regarding knowledge of transmission, covering nose and mouth while coughing and avoiding symptomatic contact can help prevent COVID-19 transmission is known by $100 \%$ HCWs and $97.7 \%$ HCWs knew that it is mainly transmitted by droplets. These results are better than the study done by Modi et al, where $62 \%$ responders knew the main mode of transmission is via respiratory droplets. ${ }^{13}$

This higher knowledge in this study might be attributed to the fact that this study was done a few months later than previous studies, and HCW might have been able to obtain more information about the disease from Infection Prevention and Control Committee of this centre, and other sources such as Ministry of Health and Population (Nepal), WHO and Center for disease control and prevention.

Till date, Remdesivir ${ }^{9}$ and Dexamethasone ${ }^{14}$ have some evidence and evidence is emerging for Tocilizumab ${ }^{15,16}$ for COVID-19 treatment. The vaccine is not available for COVID-19 is known by $89.3 \%$ HCWS in the study by Huynh which is very similar to our study where 94.1\% HCWs knew about it. ${ }^{11}$

The basic symptoms of COVID-19-fever, fatigue, sore throat, dry cough etc. was only known to $84 \%$ physicians, $69 \%$ nurses, $66.7 \%$ pharmacists and $56.2 \%$ lab technicians/radiographers. This is very similar to the study done by Huynh ${ }^{11}$ where symptoms of COVID-19 were known by $72.8 \%$ of HCW.

AGP requires the use of $\mathrm{N} 95$ respirator or equivalent. ${ }^{17}$ Approximately, $91.5 \%$ of $\mathrm{HCW}$ selieve that they can wear a surgical mask for non-AGP. Knowledge for N95 respirator was $64.1 \%$ but $87.9 \%$ of $\mathrm{HCW}$ knew that the $\mathrm{N} 95$ mask is recommended for tracheal intubation. At this time, when these masks are running short in supplies, it becomes important to use the N95 mask appropriately. Along with this, appropriate techniques of its use, removal, storage between use and reuse if not visibly soiled should be known to all HCWs. ${ }^{18}$ In this study, $46.2 \%$ and $30.2 \%$ of $\mathrm{HCW}$ s respectively don't think N95 should be used in OPD and triage room. Only $39.3 \%$ of HCWs know that it can be reused.

Awareness of proper use of PPE is known to $75.6 \%$ of HCWs and on average $85.7 \%$ of HCWs feel they should use it while intubating, performing surgery on the suspected patient and while collecting the respiratory sample. WHO has made guidelines for proper use of PPE to ensure there is no undersupply of PPE at the time of real need. ${ }^{19}$ Before caring for patients with confirmed or suspected COVID-19, HCWs must receive comprehensive training on why and when is PPE necessary, how to don and doff PPE, as well as proper care, maintenance, and disposal of PPE. HCWs also need to demonstrate competency in performing appropriate infection control practices and procedures, donning and doffing in sequence, and they should not adjust PPE (e.g., retying gown, adjusting respirator/facemask) during patient care to prevent self-contamination. ${ }^{1}$

Because there is no vaccine developed till date and that $82.3 \%$ are aware that antibiotics are not the treatment of choice, it can be inferred that HCWs have no other option but to maintain the utmost precautions while treating the patients. Basic measures like separating COVID and non-COVID patients, installing a barrier to limit contact with the patient at triage, prioritizing respirators for AGP, self-monitoring sign of illness, self-isolating, reporting any illness etc. are required for better case management and prevention of the spread of COVID-19.1,20

CPR being one of the high-risk procedure to transmit COVID-19 infection, there have been some changes in the American Heart Association and European Resuscitation Guideline for CPR of suspected or known COVID-19 patients. $^{21}$ The study showed $77.8 \%$ of HCWs know CPR of such patients referring that a good percent of HCWs of this center has already updated themselves on those CPR guidelines.

This study revealed that the majority $(87 \%)$ of HCWs gather their information through social media- Facebook, twitter etc. Interestingly, only $2.29 \%$ of HCWs referred to more authentic sources like classes, webinars, journals etc. for information. Since the knowledge of respondents in this study is quite high, they referring to social media for information shows that the use of social media is increasing and gaining trust globally. However, the government should be vigilant and scrutinize the use of social media ensuring only authentic and updated information about COVID-19 is disseminated. Also, the fact that decreased use of gadgets like mobiles can also decrease the transmission is known to only $65.9 \%$ $\mathrm{HCW}$, and their increased use of social media might increase the risk of disease transmission through these gadgets as it might act as fomites.

On average, the overall knowledge of the physicians and nurses is better than allied HCWs. However, only around half of the physicians and nurses had a higher level of medical knowledge. This highlights the need to impart further knowledge to the HCWs.

There are various limitations to this study. Firstly, this study was conducted among the HCWs in the cardiac centre of an urban area with good access to modern teaching-learning and internet facilities- webinar. So, the result might not be generalized to other multidisciplinary and rural centres. Secondly, only the knowledge was assessed and not skills. Knowledge is also obtained 
Bhandari et al. Knowledge of COVID-19 among Health Care Workers at a Tertiary Care Hospital of Nepal...

hands-on, meaning HCWs might be learning things while they practice. The $100 \%$ knowledge of HCWs regarding hand hygiene might be due to pre-existing proper hand hygiene practices in the center of study. ${ }^{22}$ Conversely, the HCWs might have theoretical knowledge about the proper use of PPE, but may not be able to apply in practice (eg. unable to doff). Not being able to measure skill limits the study in being able to triangulate the knowledge and skills. The study was conducted among the HCWs only while knowledge of non-HCWs about COVID-19 is also important to prevent its transmission.

\section{CONCLUSIONS}

HCWs from this centre have a better knowledge of COVID-19 than previous studies, though it differs significantly among physicians, nurses, and allied HCWs. As the understanding of this disease is rapidly evolving, there is a constant need for updating the HCWs regarding new protocols and guidelines for COVID-19. Also, with a shortage of PPE, the knowledge of use/reuse of appropriate
PPE becomes very important. As there is a possibility of long-term existence of SAR-CoV-2 but no definite treatment till now, COVID-19 might become an even bigger public health emergency in the future. This has increased the need to provide ongoing training on the use of appropriate PPE with the appropriate technique of donning and doffing and additional education and training to manage the surge if it occurs. Therefore, this study recommends the hospital management to arrange for periodic webinars, online modules, or other sources of authentic information for all HCWs, with special focus on allied HCWs.

\section{ACKNOWLEDGEMENTS}

We would like to acknowledge Bidha Sharma and all the health care workers of Shahid Gangalal National Heart Centre.

\section{Conflict of Interest: None.}

\section{REFERENCES}

1. Centre for Disease Control and Prevention. Interim infection prevention and control recommendation for patient with suspected/conformed coronavirus disease 2019 in health care setting [Internet]. USA: Centers for Disease Control and Prevention; 2020[cited on 2020 July 20]. Available from: https://www.cdc.gov/coronavirus/2019-nCoV/hcp/ infection-control.html. [Full Text]

2. American College of Cardiology.ACC clinical bulletin COVID-19 clinical guidance for the cardiovascular care team [Internet]. USA: American College of Cardiology; 2020[cited on 2020 July 20].Available from: https://www. acc.org// / media/Non-Clinical/Files-PDFs-ExcelMS-Word-etc/2020/02/S20028-ACC-Clinical-BulletinCoronavirus.pdf. [Full Text]

3. Hoffman SJ, Silverberg SL. Delays in global disease outbreak responses: lessons from H1N1, Ebola, and Zika. Am J Public Health. 2018 Mar;108(3):329-33. [PubMed | Full Text | DOI]

4. Selvaraj S, Lee KE, Harrell M, Ivanov I, Allegranzi B. Infection Rates and Risk Factors for Infection Among Health Workers During Ebola and Marburg Virus Outbreaks: A Systematic Review. J Infect Dis. 2018;218(suppl_5):S679-S689. [PubMed | Full Text | DOI]

5. McCloskey B, Heymann DL. SARS to novel coronavirus - old lessons and new lessons. Epidemiol Infect. 2020 Feb 5;148:e22. [마bMed | Full Text $\mid \underline{\text { DOI] }}$

6. Shafiei S, Yazdani S, Jadidfard MP, Zafarmand AH. Measurement components of socioeconomic status in health-related studies in Iran. BMC Res Notes. 2019 Jan 31;12(1):70. [릴ed | Full Text | DOI]

7. WHO. COVID-19 time line. Geneva: World Health Organization; 2020. Available from:https://www.who.int/ news-room/detail/27-04-2020-who-timeline---covid-19. [Full Text]
8. Ministry of Health and Population [Internet]. Kathmandu: Ministry of Health and Population; [cited 2020 Jul 20]. Available from: https:// covid19.mohp.gov.np. [Full Text]

9. Grein J, Ohmagari N, Shin D, Diaz G, Asperges E, Castagna A, et al. Compassionate use of Remdesivir for patients with severe Covid-19. N Engl J Med. 2020 Jun 11;382(24):2327-2336. [PubMed | Full Text | DOI]

10. WHO. Emerging respiratory viruses, including COVID-19: methods for detection, prevention, response and control [Internet]. Geneva: World Health Organization; 2020 [cited on 2020 Jul 20]. https://openwho.org/courses/ introduction-to-ncov. [Full Text]

11. Huynh G, Nguyen TN, Tran VK, Vo KN, Vo VT, Pham LA. Knowledge and attitude toward COVID-19 among healthcare workers at District 2 Hospital, Ho Chi Minh City. Asian Pac J Trop Med. 2020;13:260-5. [Full Text]

12. Zhang M, Zhou M, Tang F, Wang $\mathrm{Y}$, Nie H, Zhang L, et al. Knowledge, attitude, and practice regarding COVID-19 among healthcare workers in Henan, China. J Hosp Infect. 2020 Jun;105(2):183-187. [ubMed | Full Text | DOI]

13. Modi PD, Nair G, Uppe A, Modi J, Tuppekar B, Gharpure AS, et al. COVID-19 awareness among healthcare students and professionals in Mumbai metropolitan region: A questionnaire-based survey. Cureus. 2020 Apr 2;12(4):e7514.

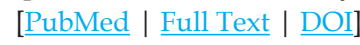

14. Horby P, Lim SW, Emberson J, Mafham M, Bell J, Linsell L, et al. Dexamethasone in Hospitalized Patients with Covid-19 - Preliminary Report. N Engl J Med. 2020 Jul 17:10.1056/ NEJMoa2021436. [라미 | Full Text | DOI]

15. Alattar R, Ibrahim TBH, Shaar SH, Abdalla S, Shukri K, Daghfal JN, et al. Tocilizumab for the treatment of severe coronavirus disease 2019. J Med Virol. 2020 May 5:10.1002/ 
Bhandari et al. Knowledge of COVID-19 among Health Care Workers at a Tertiary Care Hospital of Nepal...

\section{jmv.25964. [uuMed | Full Text | DOI]}

16. Xu X, Han M, Li T, Sun W, Wang D, Fu B, et al. Effective treatment of severe COVID-19 patients with tocilizumab. Proc Natl Acad Sci USA. 2020 May 19;117(20):10970-10975. [PubMed $\mid \underline{\text { Full Text } \mid \text { DOI] }}$

17. WHO. Advice on the use of masks in the context of COVID-19: Interim guidance [Internet]. Geneva: World Health Organization; 2020 Jun 5 [cited on 2020 Jul 20]. https://www.who.int/ publications/i/item/advice-on-theuse-of-masks-in-the-community-during-home-care-and-inhealthcare-settings-in-the-context-of-the-novel-coronavirus(2019-ncov)-outbreak. [Full Text]

18. Fischer RJ, Morris DH, van Doremalen N, Sarchette S, Matson MJ, Bushmaker T, et al. Effectiveness of N95 respirator decontamination and reuse against SARS-CoV-2 virus. Emerg Infect Dis. 2020 Jun 3;26(9):2253-2255.. [PubMed | Full Text | DOI]

19. WHO. Rational use of personal protective equipment for coronavirus disease 2019 (COVID-19): Interim guidance [Internet].Geneva: World Health Organization; 2020
Feb 27 [cited on 2020 July 20]. Available from: https:// apps.who.int/iris/bitstream/handle/10665/331215/ WHO-2019-nCov-IPCPPE_use-2020.1-eng.pdf. [Full Text]

20. WHO. Coronavirus disease (COVID-19) outbreak: rights, roles and responsibilities of health workers, including key consideration for occupational safety and health [Internet]. Geneva: World Health Organization; 2020 [cited on 2020 July 20].Available from: https://www.who.int/ docs / default-source/ coronaviruse/who-rights-rolesrespon-hw-covid-19.pdf. [Full Text]

21. ERC. European resuscitation council COVID-19 guidelines. Belgium: European Resuscitation Council; 24th April 2020 [cited on 2020 July 20]. Available from: https://www.erc. edu/sites/5714e77d5e615861f00f7d18/content_entry5ea884 fa4c84867335e4d1ff/5ea885f34c84867335e4d20e/files/ERC_ covid19_pages.pdf?1588257310. [․ㅏll Text]

22. WHO. Hand hygiene: why, how and when? [Internet]. Geneva: World Health Organization; 2020[cited on 2020 July 20]. Available from: https://www.who.int/gpsc/5may/ Hand_Hygiene_Why_How_and_When_Brochure.pdf.[Full $\underline{\text { Text }}]$

\section{(c) The Author(s) 2018 .}

This work is licensed under a Creative Commons Attribution 4.0 International License. The images or other third party material in this article are included in the article's Creative Commons license, unless indicated otherwise in the credit line; if the material is not included under the Creative Commons license, users will need to obtain permission from the license holder to reproduce the material. To view a copy of this license, visit http://creativecommons.org/licenses/by/4.0/ 